\title{
Effect of nicotine, silver acetate, and ordinary chewing gum in combination with group counselling on smoking cessation
}

\author{
E J Jensen, E Schmidt, B Pedersen, R Dahl
}

\begin{abstract}
Four hundred and ninety six smokers participated in a randomised comparison of the effect of silver acetate, nicotine, and ordinary chewing gum on smoking cessation. All were motivated to stop smoking abruptly and all had smoked at least 10 cigarettes a day for at least five years. Side effects and taste acceptability were related to outcome after six months. The participants attended nine meetings over a year, at which lectures, support, and advice about stopping smoking were given. Tobacco abstinence was confirmed by measurement of carbon monoxide in expired air. The chewing gums were used for 12 weeks. After 12 weeks there was a trend towards more abstainers in the nicotine group $(59 \%)$ than in the silver acetate $(50 \%)$ and ordinary $(45 \%)$ chewing gum groups that was not quite significant $(p=0.07)$. At 26 and 52 weeks the number of cigarette abstainers was similar in the three treatment groups. Subjects in the nicotine chewing gum group had a longer mean time before relapse than those in the silver acetate and ordinary chewing gum groups. Mean success rates for all subjects combined at 12, 26, and 52 weeks were $52 \cdot 8 \%, 39 \cdot 7 \%$, and $23 \cdot 3 \%$. The side effects of nicotine and silver acetate chewing gum were generally mild and transient, and unimportant except for mouth irritation from silver acetate, which had a negative effect on outcome, and the low taste acceptability of nicotine, which had a strong negative influence on the success rate. The results suggest a short term effect of nicotine chewing gum on smoking cessation, but the abstinence rates after one year were generally disappointing.
\end{abstract}

Department of

Respiratory Disease, University Hospital, Aarhus, Denmark

E J Jensen

E Schmidt

B Pedersen

R Dahl

Address for reprint requests: Dr E J Jensen, Department of Respiratory Medicine,

University Hospital,

Noerrebrogade, DK-8000

Aarhus C, Denmark.

Accepted 14 August 1990
Smoking appears to be the greatest single, preventable cause of disease, disability, and premature death. ${ }^{1}$ Although this knowledge is common, smokers are still numerous and effective smoking cessation programmes are still needed. Psychosocial aspects and learned reflexes have been proposed as the main factors behind the smoking habit. ${ }^{2-4}$ Some smoking cessation programmes have therefore included silver acetate chewing gum, which gives tobacco smoke a bad taste, and some of the studies have shown short term benefit from this approach..$^{5-8}$ Others have claimed that nicotine addiction is the main reason for smoking ${ }^{910}$ and nicotine chewing gum has been shown to be better than placebo in some smoking cessation programmes, ${ }^{11-20}$ though others have not been able to confirm this. ${ }^{2122}$ The present study was designed to compare the influence on smoking cessation of silver acetate, nicotine, and ordinary chewing gum in conjunction with group counselling and information and support related to stopping smoking. Associations between side effects and taste acceptability and outcome were looked for.

\section{Methods}

Silver acetate chewing gum (Fertin Laboratories, Vejle, Denmark) contains silver acetate $6 \mathrm{mg}$. The maximum daily consumption of this compound was restricted to six pieces of gum.

Nicotine chewing gum (Nicorette, Lundbeck, Denmark) contained $2 \mathrm{mg}$ buffered nicotine and could be used as needed.

Ordinary unflavoured, sugar free chewing gum (V6, Fertin Laboratories, Vejle, Denmark) was given to be used without restriction.

After six weeks all subjects were told that consumption of their chewing gum should be reduced gradually to zero over the following six weeks.

\section{STUDY DESIGN}

Individuals more than 18 years of age and motivated to stop smoking abruptly and completely were invited to participate. They had to have been regular smokers for more than five years with a daily tobacco consumption of more than 10 cigarettes. Five hundred and seventeen smokers were randomised to 24 smaller groups and each group was randomly allocated to treatment.

The participants came to the clinic one week before quitting day and were informed about the aim and design of the study. They were asked to attend nine meetings at the clinic during the following year, the first on quitting day and subsequently after $1,2,3,4$, $6,12,26$, and 52 weeks. The primary end point was total abstinence from smoking; reentry into the study was not allowed. At the meetings the participants met in small groups 
to support each other. Through lectures, films, posters, and booklets they were given information about health risks of smoking, health improvements after stopping smoking, possible reasons for the smoking habit, behavioural methods for overcoming circumstances leading to the urge to smoke, and dietary advice on avoiding weight gain. At each meeting claims of tobacco abstinence were controlled objectively by measuring the content of carbon monoxide in expired air (Ecolyzer CO-monitor Energetics Science, Hawthorne, New York). The concentration of carbon monoxide in expired air has been shown to reflect the concentration of carboxyhaemoglobin in blood accurately ${ }^{23}$ and is a reliable measure of tobacco abstinence for the previous 24 hours. Participants with a concentration greater than $4 \mathrm{ppm}$ were regarded as trial failures.

Before stopping smoking all participants filled in questionnaires on their age and sex and their estimation of the degree of physiological nicotine dependence. ${ }^{24}$ The amount of chewing gum used was monitored at each meeting. Ratings of taste acceptability and side effects of the chewing gums were reported weekly during the first five weeks and their influence on abstainer rates after 26 weeks were evaluated.

\section{ANALYSIS}

Abstainer rates after 26 weeks were expected to be $60 \%, 40 \%$ and $20 \%$ in the nicotine, silver acetate, and placebo groups. With a type 1 error $(2 \alpha)$ and a type 2 error $(\beta)$ of 0.05 the sample sizes should include 163 subjects in each of the active groups and 69 in the inactive group. ${ }^{25}$ The BMDP statistic program package was used. ${ }^{26}$ Success rates and ratings of the severity of side effects and of taste acceptability were evaluated by Pearson's $\chi^{2}$ test. Uniformity in demographic variables between treatment groups was tested with Pearson's $\chi^{2}$ and Student's $t$ tests. For testing time dependent changes McNemar's test of symmetry was used. Equality of survival distributions of the treatment groups was tested with the tests of Mantel-Cox and Breslow. In all tests the significance limit was 0.05 and two tailed tests were used.

ETHICS

The smokers gave their informed consent to participate. The study had the approval of the ethical committee of Aarhus county, and was performed in accordance with the Helsinki II declaration.

\section{Results}

Five hundred and seventeen smokers attended the information meeting and 496 subjects could be included in the analysis, with 211,203 , and 82 in the nicotine, silver acetate, and ordinary chewing gum groups. Seven had moved from the city, seven had a disease that was incompatible with participation in the trial, two died during the trial, and five were admitted to hospital and unable to attend the meetings. The treatment groups were similar with respect to demographic variables (table 1) and number of withdrawals.

The percentages of cigarette abstainers after 12,26 , and 52 weeks are shown in table 2 . After 12 weeks there was a trend towards more abstainers in the nicotine chewing gum group $(59 \%)$ than in the silver acetate $(50 \%$; $\mathrm{p}<0.08)$ or ordinary chewing gum group $(45 \% ; \mathrm{p}<0.07)$. Participants in the nicotine group had a longer mean (SD) time before relapse $(59 \cdot 0(7 \cdot 1)$ days) than the silver acetate group (45.7 (6.1) days; $p<0.05)$ or the ordinary chewing gum group (43.8 (9.0) days; $\mathrm{p}<0.05)$. At 26 and 52 weeks, however, there

Table 1 Demographic data (mean (SD) values) for the treatment groups

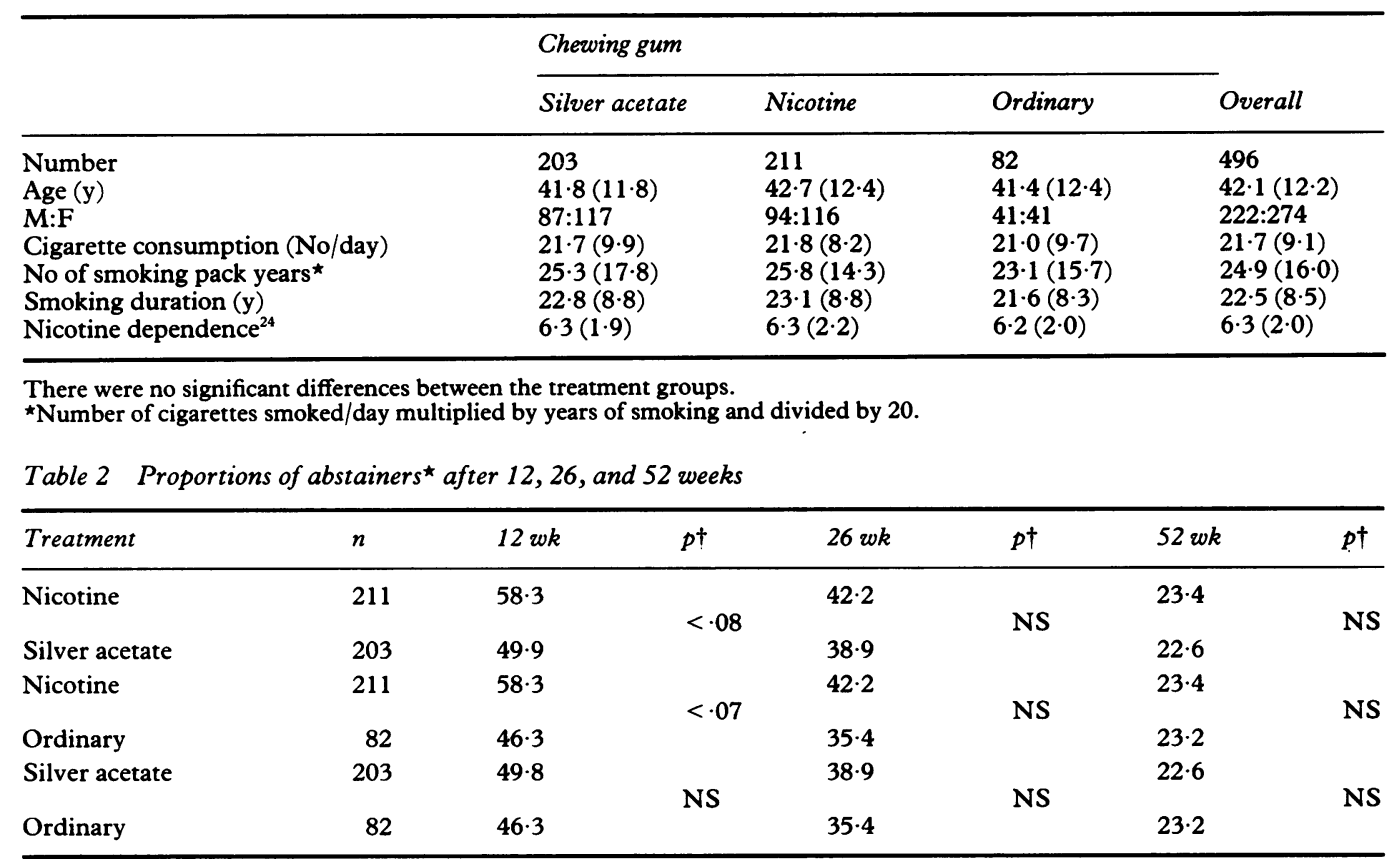

* Percentages of participants who were abstinent from the start of the trial until evaluation.

†Significance of the pairwise comparisons of abstainers between the treatment groups. 
was no difference between treatment groups in the number of subjects abstaining from cigarettes. No group effects were observed at 12,26 , or 52 weeks. Mean success rates for all subjects combined at 12,26 , and 52 weeks were $52 \cdot 8 \%$, $39 \cdot 7 \%$, and $23 \cdot 8 \%$.

The mean (SD) daily consumption of silver acetate, nicotine, and ordinary chewing gum consumption was $2 \cdot 75(2 \cdot 0), 9 \cdot 3(5 \cdot 5)$, and $12 \cdot 4$ $(7 \cdot 4)$ pieces. After 26 weeks $15 \%$ of abstainers in the nicotine group, $4 \%$ of abstainers in the silver acetate group, and no abstainers in the ordinary chewing gum group were still using the chewing gum. The most important side effects were irritation of the mouth, borborygmi, flatulence, and nausea. Irritation of the mouth was more severe in groups having active chewing gum than in those having ordinary chewing gum $(p<0.05)$. Side effects did not influence success rates in participants treated with nicotine or ordinary chewing gum but irritation of the mouth tended to reduce the success rate in the silver acetate group $(\mathrm{p}<0.06)$. There was a decrease between meetings 1 and 3 in the severity of mouth irritation and nausea in the nicotine group $(\mathrm{p}<0.05)$, and in borborygmi and nausea in the silver acetate group $(p<0.02)$. The taste of ordinary chewing gum was better accepted than that of silver acetate $(p<0.0001)$ or nicotine $(\mathrm{p}<0.0001)$ chewing gum, though the acceptability of nicotine chewing gum improved within two weeks of treatment $(\mathrm{p}<0.0001)$. Poor acceptability reduced the success rate in the nicotine group as $75 \%$ with high taste acceptability were abstinent after 26 weeks compared with $17 \%$ when acceptability was low $(\mathrm{p}<0.0001)$.

\section{Discussion}

Randomisation of subjects in this study was satisfactory according to demographic variables and treatments were controlled by ordinary chewing gum. The study was not blind because the daily consumption of silver acetate had to be restricted to a maximum of six pieces to avoid the risk of argyria. ${ }^{27}$ The open design of the study probably had little influence on success rates as the final outcome in the inactive treatment group was similar to the outcome in the active treatment groups. In a recent study of nicotine chewing gum most participants were able to classify themselves correctly with respect to treatment after a short time, and this was shown to have no influence on the success rate. ${ }^{28}$ The chewing gums were available for 12 weeks. Participants who wished to use chewing gum for a longer time continued to receive this at the clinic; they were not excluded from the study as we did not want to interrupt their attempt to stop smoking.

Comparison of mean relapse times for the treatment groups showed short term superiority of nicotine treatment over inactive treatment. ${ }^{1621}$ A long term effect was not confirmed, however, even though the outcome in the nicotine group in the present study was similar to success rates in earlier studies with nicotine chewing gum. ${ }^{12-15} 17$ The cigarette abs- tinence rate with inactive treatment was higher in our study than in previous studies with a similar design, where abstinence rates have rarely exceeded $20 \%$ after 26 weeks. ${ }^{1314161721}$ The higher success rate seen with inactive treatment in this study may be due to the impact of the group sessions, which may have strengthened the motivation and spirits of all the groups. Studies with nicotine chewing gum with no support group sessions have reported very low success rates, ${ }^{1822}$ suggesting that group support arrangements contributes appreciably to the effectiveness of smoking cessation trials.

Our method of assessing tobacco abstinence (carbon monoxide in expired air) is known to be reliable for smoking over the previous 24 hours. Subjects who had relapsed but who had been able to abstain from smoking for 24 hours might be counted as abstainers incorrectly. Participants were not told how long the effect of smoking on carbon monoxide continued, however, and there were only a few cases in which wrongly claimed abstinence was suspected. The problem was similar for all treatment groups and cannot explain the lack of any long term difference in outcome. Fifteen per cent of the abstainers in the nicotine group still used nicotine chewing gum after 26 weeks-possibly because the period allowed for nicotine substitution was insufficient or because too small a dose of nicotine per chewing gum was given. An increased dose of nicotine might have enhanced the results.

Side effects of nicotine chewing gum, as reported previously, were mild, ${ }^{141621}$ transient $\mathrm{t}^{1417}$ and without influence on success rate. ${ }^{21}$ An exception from this was poor taste acceptance of nicotine chewing gum, which had a profound negative influence on success rate. Participants with a low tolerance for nicotine chewing gum might have done better if treated with pieces containing $4 \mathrm{mg}$ of nicotine as this would have lowered the daily number of pieces of chewing gum required, but taste acceptance might on the other hand have been poorer because of the strong taste. We did not observe the short term benefit from silver acetate chewing gum previously reported. ${ }^{8}$ The difference was probably caused by different study designs.

The present study found only a short term advantage from treatment with nicotine chewing gum and no advantage from treatment with silver acetate chewing gum by comparison with ordinary chewing gum. Cigarette abstinence rates after 26 and 52 weeks were disappointing. This result and the variability in success rates observed in smoking cessation studies calls for the development of more effective and possibly individualised smoking cessation programmes.

\footnotetext{
1 Fielding JE. Smoking: Health effects and control. $N$ Engl J Med 1985;313:491-8.

2 Bergen BJ, Olesen E. Some evidence for a peer group hypothesis about adolescent smoking. Health Educ J 1963;21:113-9.

3 Solomon RL, Corbitt JD. An opponent process theory of motivation. II: Cigarette addiction. J Abnorm Psychol 1973;81:119-45.
} 
4 Smith GM. Personality and smoking. A review of the empirical literature. In: Hunt WA, ed. Learning mechanisms in smoking. Chicago: Aldine, 1970:42-63.

5 Bernstein DA, Glasgow RE. The modification of smoking behavior. In: Pomerleau OF, Brady JP, eds. Behavioral medicine: theory and practice. Baltimore: Williams and Wilkins, 1979:233-53.

6 Lichtenstein E, Penner MR. Long term effects of rapid smoking treatment for dependent smokers. Addict Behav 1977;2:1-12.

7 Schmidt F. Raucherentwöhnung durch anti-raucher Raugummi dragges im doppelblindversuch. Münch Med Wochenschr 1977;119:1343-4.

8 Malcolm R. Silver acetate gum as a smoking deterrent. Chest 1986;89:107-11.

9 Jarvik ME. Biological factors underlying the smoking habit. In: Jarvik ME, Cullen JW, Gritz ER, Vogt TM, West LJ, eds. Research on smoking behavior. Washington DC: eds. Research on smoking behavior. Washington DC: ment of Health, Education and Welfare publication (ADM) 78-581.

10 Schacter S. Pharmacological and psychological determinants of smoking. Ann Intern Med 1978;88(4):104-14.

11 Hall MS, Tunstall CD, Ginsberg D, Benowitz N, Jones RT Nicotine gum and behavioral treatment: A placebo controlled trial. J Consult Clin Psychol 1987;55:603-5.

12 Fägerström K-O. Effects of nicotine chewing gum and follow-up appointments in physician-based smoking cessation. Prev Med 1984;13:517-27.

13 Hjalmerson AIM. Effect of nicotine chewing gum in smoking cessation. $J A M A$ 1984;252:2835-8.

14 Jarvis MJ, Raw M, Russell MAH, Feyerabend C. Randomized controlled trial of nicotine chewing gum. Br Med $J$ 1982;285:537-40.

15 Raw M, Jarvis MJ, Feyerabend C, Russell MAH. Comparison of nicotine chewing gum and psychological treatment for dependent smokers. $\mathrm{Br}$ Med J 1980;281:481-4.

16 Schneider NG, Jarvik ME, Forsythe AB, Read LL, Elliot ML, Schweiger A. Nicotine chewing gum in smoking cessation: A placebo-controlled double-blind trial. Addict Behav 1983;8:253-61.

17 Tonnesen P, Fryd V, Hansen M, Helstedt J, Gunnersen AB, Forchammer H, Stockner $M$. Effect of nicotine chewing gum in combination with group counseling on the cessation of smoking. N Engl J Med 1988;318:15-8.

18 Russel MAH, Merriman R, Stapleton F, Taylor W. Effect of nicotine chewing gum as an adjunct to general practitioners' advice against smoking. Br Med J 1983;287:1782-5.

19 Jarvik ME, Schneider NG. Degree of addiction and effectiveness of nicotine gum therapy for smoking cessation Am J Psychiatry 1984;141:790-1.

20 Fägerström K-O. A comparison of psychological and pharmachological treatment in smoking cessation. J Behav Med 1983;5:343-51.

21 Fee WM, Steward MJ. A controlled trial of nicotine chewing gum in a smoking withdrawal clinic. Practitioner 1982; 226:148-51.

22 Crofton J, Cambel IA, Cole PV, et al. Comparison of four methods of smoking withdrawal in patients with smoking related diseases. Br Med J 1983;286:595-7.

23 Jarvis MJ, Russell MAH, Salooje Y. Expired air carbon monoxide: A simple breath test of tobacco smoke intake. Br Med J 1980;281:484-5.

24 Fägerström K-O. Measuring degree of physical dependence to tobacco smoking with reference to individualization of treatment. Addict Behav 1978;3:235-41.

25 Friedmann LM, Furberg CD, DeMets DL. Fundamentals of clinical trials. Bristol: Wright, 1982:69-88.

26 Dixon WJ, ed. BMDP statistical software. Los Angeles: University of California Press, 1985.

27 Jensen EJ, Rungby J, Hansen JC, Scmidt E, Pedersen B, Dahl R. Serum concentrations and accumulation of silver in skin during three months treatment with an antismoking chewing gum containing silver acetate. Hum Toxicol 1988;7:535-40.

28 Hughes JR, Krahn D. Blindness and the validity of the doubleblind procedure. J Psychopharmacol 1985;5: 138-42. 